\title{
Determination of $U$ isotopic ratios in environmental samples by ICP-MS
}

\author{
Shigeo Uchida, ${ }^{a}$ Rafael García-Tenorio, $^{b}$ Keiko Tagami $^{a}$ and Manuel García-León ${ }^{c}$ \\ ${ }^{a}$ Environmental and Toxicological Sciences Research Group, National Institute of \\ Radiological Sciences, Anagawa 4-9-1, Inage-ku, Chiba-shi 263-8555 Japan. \\ E-mail: s_uchida@nirs.go.jp \\ ${ }^{b}$ Dept. Física Aplicada, Universidad de Sevilla, Avda Reina Mercedes, 2, 41012-Sevilla, Spain \\ ${ }^{c}$ Facultad de Física, Universidad de Sevilla, Apdo 1065, 41080-Sevilla, Spain
}

Received 17th February 2000, Accepted 17th April 2000
Published on the Web 14th June 2000

Inductively coupled plasma mass spectrometry (ICP-MS) has been used for the determination of trace elements in a variety of materials. For uranium, the concentration of ${ }^{238} \mathrm{U}$ can be measured with a detection limit of less than $0.1 \mathrm{ppt}$ in a few minutes. However, because of the extremely low ${ }^{234} \mathrm{U}$ concentrations in environmental materials, it is necessary to separate $U$ from the matrices and to remove interfering elements from the sample solution for measurement of the ${ }^{238} \mathrm{U} /{ }^{234} \mathrm{U}$ ratio by ICP-MS. In this study, a simple and rapid separation method for $\mathrm{U}$ with an extraction chromatographic resin (TEVA resin) was developed for ICP-MS and the $\mathrm{U}$ isotopic ratios in phosphogypsum samples, collected in Spain, were measured. The resin efficiently retained U in $6 \mathrm{M} \mathrm{HCl}$ medium and more than $98 \%$ of the $\mathrm{U}$ was easily eluted with the first $30 \mathrm{~mL}$ of $0.1 \mathrm{M} \mathrm{HNO}_{3}$. The separated solutions were free from most of the matrix elements and the concentrations of $U$ in the solutions ranged from 35 to $70 \mathrm{ppb}$. The ${ }^{238} \mathrm{U}^{234} \mathrm{U}$ isotopic ratios in the solutions were measured by ICP-MS. Moreover, due to the presence of a higher number of ${ }^{235} \mathrm{U}$ atoms in comparison with ${ }^{234} \mathrm{U}$, the ${ }^{238} \mathrm{U} /{ }^{235} \mathrm{U}$ isotopic ratios were also determined with high precision by ICP-MS. The results obtained agreed well with the ratios measured by alpha-spectrometry. The method for this determination is more rapid than alpha-spectrometry, and is considered to be more suitable for environmental monitoring.

\section{Introduction}

Inductively coupled plasma mass spectrometry (ICP-MS) has been used with great success for the accurate and precise determination of trace elements in environmental materials. Due to its low detection limits, analytical speed, lack of chemical interference, and multielemental capability, the method has been successfully applied to the determination of more than 30 elements in environmental samples without any chemical separations. ${ }^{1-4}$ This technique has proved to be powerful enough for the determination of long-lived radionuclides, such as ${ }^{238} \mathrm{U},{ }^{237} \mathrm{~Np},{ }^{232} \mathrm{Th},{ }^{99} \mathrm{Tc}$ and ${ }^{239} \mathrm{Pu}$, in environmental samples. ${ }^{5-12}$ Precise determination of $\mathrm{U}$ and $\mathrm{Th}$ without radiochemical separation can be achieved for water samples, ${ }^{13-15}$ or soil samples in which treated amounts are about $0.1 \mathrm{~g} .{ }^{4}$

In relation to isotopic ratio studies, thermal ionization mass spectrometry (TIMS) has been the conventional method for high precision analysis, but this technique is time consuming and expensive. Recently, isotopic ratio measurements using ICP-MS have been reported. ${ }^{16-20}$ However, there is not much information in the current literature on the capability of ICPMS for measuring ${ }^{238} \mathrm{U} /{ }^{234} \mathrm{U}$ ratios in environmental samples. ${ }^{11,12,21,22}$ This is mostly due to the extremely low ${ }^{234} \mathrm{U}$ mass concentration in these matrices. In fact, by assuming radioactivity equilibrium in environmental samples, the ${ }^{238} \mathrm{U} /{ }^{234} \mathrm{U}$ isotopic ratio can be expected to be around $1.8 \times 10^{4}$. Nevertheless, the knowledge of such ratios can give relevant information on natural systems. ${ }^{23}$ It reveals, for instance, the existence of anthropogenic inputs in aquatic systems ${ }^{24}$ or can help to date geological samples through the U/Th dating method. Also, the determination of the ${ }^{238} \mathrm{U}^{235} \mathrm{U}$ ratio is useful, for instance, for environmental studies around nuclear plants. It is clearly worthwhile, therefore, to investigate whether ICP-MS could be applied to the determination of $U$ isotope ratios.

Traditional $\mathrm{U}$ determination by ICP-MS requires almost no chemistry work. However, the extremely low ${ }^{234} \mathrm{U}$ mass concentration at environmental levels makes it necessary to carry out some preconcentration processes, i.e. some chemical manipulations, so as to sufficiently decrease the limits of detection and be able to give true $U$ isotope ratios.

In recent years, selective extraction chromatographic resins, such as TEVA, TRU and UTEVA resins, have been developed by EIChroM Industries Inc. (Darien, Illinois, USA) for the separation of actinides from solutions. A novel and simple method of separation and concentration of U-isotopes from environmental samples, based on the use of these resins, has been developed and validated. ${ }^{25-29}$ In particular, we are interested in TEVA resins from the viewpoint of $U$ determination by ICP-MS. The reasons are as follows.

(1) Adsorption of U by TEVA resin under suitable acid solution conditions is higher than that by UTEVA resin.

(2) Desorption of U from TEVA resin by a weak nitric acid solution is achieved more easily than for the other two resins. This means that TEVA resin can concentrate $U$ in a small amount of weak nitric acid solution. It is also preferable that the final solution is less than $0.5 \mathrm{M} \mathrm{HNO}_{3}$ for easy determination by ICP-MS.

(3) TRU resin shows the highest adsorption characteristics for $U$, but desorption by a small amount of a weak nitric acid solution seems to be difficult, because of the relatively high adsorption factor under low $\mathrm{pH}$ acid solution conditions.

In this paper, we separate and concentrate $U$ in environmental samples by using TEVA resins. Later ICP-MS will be used to determine the $\mathrm{U}$ isotopic ratios in some phosphogypsum samples.

This journal is (C) The Royal Society of Chemistry 2000 


\section{Experimental}

\section{Samples}

Phosphogypsum samples (mostly $\mathrm{CaSO}_{4} \cdot 2 \mathrm{H}_{2} \mathrm{O}$ ), the byproduct formed in the production of phosphoric acid from phosphate rocks, were collected in Spain. They were chosen to test the performance of the chemical separation of $U$ and the $U$ ratio determination because they showed relatively high $\mathrm{U}$ concentrations. The ${ }^{238} \mathrm{U},{ }^{235} \mathrm{U}$ and ${ }^{234} \mathrm{U}$ concentrations had been previously determined by alpha-spectrometry, ${ }^{30}$ which served to validate the method.

\section{Reagents}

Prepacked columns of TEVA resin, including $c a .2 \mathrm{~mL}$ of the resin, were used in the experiments. Standard, washing and stripping solutions were prepared with nitric and hydrochloric acids of ultra-analytical grade (Kanto Chemical Co. Inc., Tokyo, Japan). Deionized water ( $>17 \mathrm{M} \Omega$ ) was used throughout the work.

\section{Sample preparation}

The samples were prepared according to a newly developed procedure, which is shown schematically in Fig. 1. A $0.1 \mathrm{~g}$ sample was placed in a polytetrafluoethylene (PTFE) beaker covered with a PTFE cover and digested under reflux with conc. $\mathrm{HNO}_{3}$ for $2 \mathrm{~h}$ at $120-140{ }^{\circ} \mathrm{C}$ on a hot-plate. After this step, the cover was removed and the sample evaporated to dryness. The residue was then dissolved into $10 \mathrm{~mL}$ of conc. $\mathrm{HCl}$. The solution was filtered to remove insoluble materials. The filter was rinsed with $10 \mathrm{~mL}$ of water which was added to the filtrate. After all these processes the final solution to be passed through the TEVA resin was $c a .20 \mathrm{~mL}$ of $c a .6 \mathrm{M} \mathrm{HCl}$.

We considered that this procedure could not have completely digested the phosphogypsum. However, we decided to use this wet-digestion method, because it was the one used for the $\mathrm{U}$ determination by alpha-spectrometry. ${ }^{30}$ In order to compare the results by ICP-MS with those obtained by alphaspectrometry, it was preferable if the digestion procedures were the same.

\section{Separation and concentration}

Isolation of $U$ and purification of the solution was done with a TEVA resin. The isolation step is based on a strong tendency for the oxidised form of $U$ to be retained on the resin column

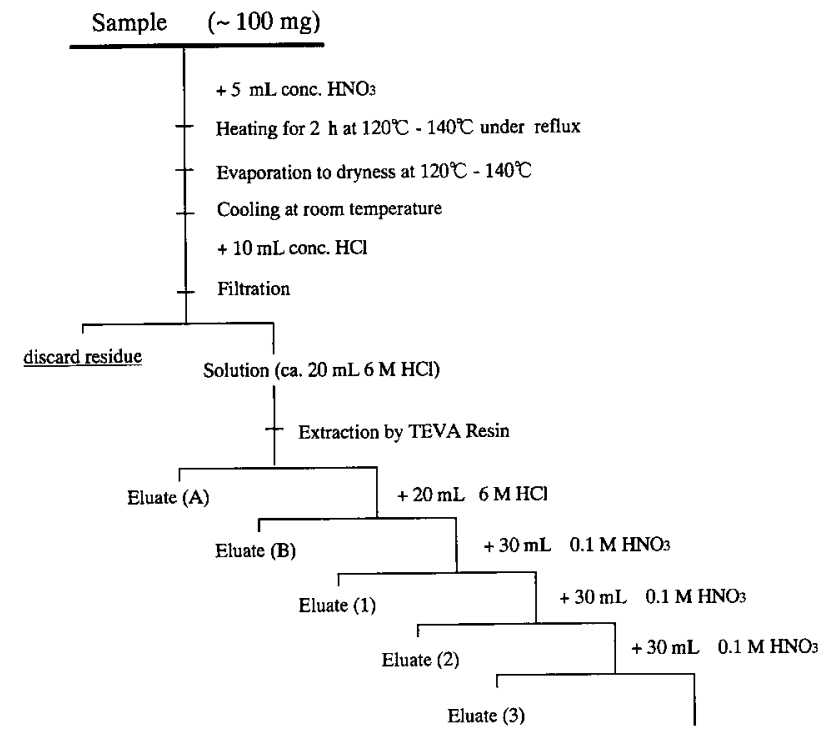

Fig. 1 Experimental scheme for the separation of $U$ in phosphogypsum sample. at high $\mathrm{HCl}$ molarity. This affinity disappears at low acid condition, e.g., $0.1 \mathrm{M} \mathrm{HNO}_{3}$ or $0.1 \mathrm{M} \mathrm{HCl}^{25}$ Thus, after conditioning the resins with $6 \mathrm{M} \mathrm{HCl}$, the solutions obtained by wet-digestion of the samples, in which the acid strength was also $6 \mathrm{M} \mathrm{HCl}$, were passed through the columns, producing the eluate A.

Next, the resin column was washed with an additional $20 \mathrm{~mL}$ of $6 \mathrm{M} \mathrm{HCl}$ (eluate B) to eliminate other elements that have low fixation on the resin. The $\mathrm{U}$ retained was finally eluted from the resin by passing three volumes of $30 \mathrm{~mL}$ of $0.1 \mathrm{M} \mathrm{HNO}_{3}$ (eluates 1, 2 and 3). The flow-rate was kept at about $1 \mathrm{~mL} \mathrm{~min}{ }^{-1}$ during the experiments. $0.1 \mathrm{M} \mathrm{HNO}_{3}$ was selected as a stripping solution, because $\mathrm{Cl}$ originating from $\mathrm{HCl}$ forms complexes with several elements, such as $\mathrm{Au}$ and $\mathrm{Hg}$. When $\mathrm{U}$ isotopes were measured by a quadrupole type ICP-MS, these complexes, especially, ${ }^{197} \mathrm{Au}^{37} \mathrm{Cl},{ }^{198} \mathrm{Hg}^{37} \mathrm{Cl}$ and ${ }^{200} \mathrm{Hg}^{35} \mathrm{Cl}$, have to be rejected in order to avoid interferences. In this study, we tried to determine directly the concentration of $U$ isotopes in the final solution by ICP-MS. For direct measurement of an element with an ICP-MS, a high acid solution is harmful to the detector. The $0.1 \mathrm{M} \mathrm{HNO}_{3}$ solutions can be directly introduced into the ICP-MS, if other matrix elements in the final solutions have been removed during separation and purification procedures. Moreover, due to the low concentration of ${ }^{234} U$ in the samples, it is necessary to make the counting time as long as possible. High concentrations of matrix elements in the final solutions damage the introductory path and detector of the ICP-MS. Both separation of $U$ from other elements and good recovery of $U$ are necessary for the determination of $U$ isotopic ratios by ICP-MS.

\section{Measurements}

A Yokogawa (Tokyo, Japan) PMS-2000, quadrupole type ICP-MS, was used for the analysis of $U$ isotopes in the samples. The instrumental parameters are summarised in Table 1. Under these analytical conditions, the oxide formation of $\mathrm{Ce}$ was found to be less than $2 \%$. As an internal standard, Bi was used to compensate for changes in the analytical results during operation. Also, a standard solution was prepared from Spex multielemental plasma standards (XSTC 13, Spex Industries, Edison, NJ, USA), and used for calibration purposes. Three replicate measurements were done for every sample, looking for 2, 50 and $150 \mathrm{~s}$ counting times for ${ }^{238} \mathrm{U},{ }^{235} \mathrm{U}$ and ${ }^{234} \mathrm{U}$, respectively, in each run.

\section{Results and discussion}

\section{Effectiveness of the separation method}

A certain amount of each eluate (eluates A, B, 1, 2 and 3) obtained from two phosphogypsum samples (identified as A and B), was measured by ICP-MS. The amounts of $U\left({ }^{238} \mathrm{U}\right)$ in each eluate are listed in Table 2.

It was clear that only a negligible amount of $U$ was detected in the drain of the load solution and the washing solution of $6 \mathrm{M} \mathrm{HCl}(20 \mathrm{~mL} \times 2)$. Almost all $\mathrm{U}$ in the samples was concentrated in the first strip solution of $0.1 \mathrm{M} \mathrm{HNO}_{3}$. Most of

Table 1 Operating conditions of ICP-MS

\begin{tabular}{ll}
\hline Rf power & $1240 \mathrm{~W}$ \\
Coolant gas flow rate & $13 \mathrm{~L} \mathrm{~min}^{-1}$ \\
Auxiliary gas flow rate & $1.2 \mathrm{~L} \mathrm{~min}^{-1}$ \\
Carrier gas flow rate & $0.83 \mathrm{~L} \mathrm{~min}^{-1}$ \\
Distance from load coil & $5.4 \mathrm{~mm}$ \\
$\quad$ to aperture & $300 \mathrm{~ms}$ for ${ }^{234} \mathrm{U}, 100 \mathrm{~ms}$ for \\
Dwell time & ${ }^{235} \mathrm{U}$ and $4 \mathrm{~ms}$ for ${ }^{238} \mathrm{U}$ \\
Number of sweeps & 500 \\
Replication & 3 \\
\hline
\end{tabular}


Table 2 Uranium results $\left({ }^{238} \mathrm{U}\right.$ in $\left.\mathrm{ng}\right)$ in the five eluates obtained from two phosphogypsum samples by the application of the radiochemical method in Fig. 1

\begin{tabular}{|c|c|c|c|c|c|}
\hline Sample A & U/ng & $\mathrm{U}$ in eluate $(\%)$ & Sample B & U/ng & $\mathrm{U}$ in eluate $(\%)$ \\
\hline Eluate A & $7.56 \pm 6.95$ & 0.47 & Eluate A & $9.8 \pm 6.9$ & 0.68 \\
\hline Eluate B & $8.72 \pm 5.50$ & 0.50 & Eluate B & $5.3 \pm 6.4$ & 0.37 \\
\hline Eluate 1 & $1603 \pm 8$ & 98.86 & Eluate 1 & $1415 \pm 9$ & 98.77 \\
\hline Eluate 2 & $0.94 \pm 0.08$ & 0.06 & Eluate 2 & $2.0 \pm 1.0$ & 0.15 \\
\hline Eluate 3 & $1.30 \pm 0.7$ & 0.08 & Eluate 3 & $0.38 \pm 0.10$ & 0.03 \\
\hline Total & $1622 \pm 12$ & 100.01 & Total & $1433 \pm 13$ & 100.0 \\
\hline
\end{tabular}

the matrix elements passed through the column with the $6 \mathrm{M}$ $\mathrm{HCl}$ solution, with the exception of Fe. Some Fe was eluted with the $6 \mathrm{M} \mathrm{HCl}$ solution (eluate A), but the rest behaved in a similar manner to $\mathrm{U}$. The concentration of $\mathrm{Fe}$ in eluate 1 was more than $100 \mathrm{ppm}$. This might be due to the formation of a strongly adsorbed negatively charged iron complex in the $6 \mathrm{M}$ $\mathrm{HCl}$ conditions. The samples used in this study contained a relatively high concentration of $\mathrm{Fe}$. We thought that some $\mathrm{Fe}-$ $\mathrm{Cl}$ complex ions in the introductory solution were adsorbed on the resin, but the complex ions exceeded the capacity of the resin for adsorption and were eluted with the solution (eluate A). The ions adsorbed on the resin then were desorbed with $0.1 \mathrm{M} \mathrm{HNO}_{3}$ solution (eluate 1).

Our results show that the TEVA resin efficiently retained $U$ in $6 \mathrm{M} \mathrm{HCl}$ medium, while it was easily eluted with the first $30 \mathrm{~mL}$ of $0.1 \mathrm{M} \mathrm{HNO}_{3}$. The concentration of $\mathrm{U}$ isotopes in the solution can be determined directly by ICP-MS, because major elements were removed from the solution by the resin. In our experiment, we finally collected $\mathrm{U}$ in $30 \mathrm{~mL}$ of $0.1 \mathrm{M} \mathrm{HNO}_{3}$, but we thought that $\mathrm{U}$ could be concentrated in the strip solution, of which the volume is less than $30 \mathrm{~mL}$.

Table $3{ }^{238} \mathrm{U}$ specific activities $\left(\mathrm{mBq} \mathrm{g}^{-1}\right)$ determined in two phosphogypsum samples by ICP-MS and alpha-spectrometry ${ }^{a}$

\begin{tabular}{lll}
\hline & ${ }^{238} \mathrm{U} / \mathrm{mBq} \mathrm{g}^{-1}$ & \\
\cline { 2 - 3 } Sample & ICP-MS & Alpha-spectrometry \\
\hline Sample A & $179 \pm 2$ & $170 \pm 7$ \\
Sample B & $161 \pm 2$ & $170 \pm 8$
\end{tabular}

${ }^{a} \pm: 1 \sigma$ statistical error by ICP-MS and $1 \sigma$ counting error by alpha-spectrometry.

Table 4 Analytical results obtained in the determination of the Uisotopes in three phosphogypsum samples and a blank sample ${ }^{a}$

\begin{tabular}{|c|c|c|c|}
\hline \multirow[b]{2}{*}{ Sample } & ${ }^{238} \mathrm{U}$ counts & ${ }^{235} \mathrm{U}$ counts & ${ }^{234} \mathrm{U}$ counts \\
\hline & $2 \mathrm{~s}$ & $50 \mathrm{~s}$ & $150 \mathrm{~s}$ \\
\hline $\mathrm{C}$ & $797778 \pm 14592$ & $138372 \pm 3220$ & $3573 \pm 102$ \\
\hline $\mathrm{D}$ & $799421 \pm 11815$ & $138903 \pm 2285$ & $3538 \pm 134$ \\
\hline $\mathrm{E}$ & $1424194 \pm 27592$ & $241231 \pm 5345$ & $5978 \pm 135$ \\
\hline Blank & $403 \pm 15$ & $204 \pm 13$ & $358 \pm 9$ \\
\hline
\end{tabular}

The results obtained previously in other aliquots of the same samples by alpha-spectrometry are listed in Table $3 .^{30}$ The results agree well for both samples A and B. It can be deduced that no appreciable fraction of $\mathrm{U}$ remained in the column. Consequently, the solutions of $0.1 \mathrm{M} \mathrm{HNO}_{3}$, corresponding to eluate 1, contain more than $98 \%$ of the $\mathrm{U}$ originally present in the sample, and are free from most of the matrix elements except Fe. These solutions contain around $50 \mathrm{ppb}$ of $\mathrm{U}$. Therefore, this separation method can be used for the determination of the ${ }^{238} \mathrm{U}^{234} \mathrm{U}$ and ${ }^{238} \mathrm{U} /{ }^{235} \mathrm{U}$ isotopic ratios by ICP-MS.

\section{Isotopic ratios of $\mathrm{U}$ in phosphogypsum samples}

The $\mathrm{U}$ isotope amounts were measured by ICP-MS in the purified solutions (eluates 1) obtained from three more phosphogypsum samples (samples C, D and E). These experimental results are compiled in Table 4 . The results obtained for a blank sample are also included. The blank sample underwent exactly the same chemical separation procedure as the phosphogypsum samples.

From these results, we drew two conclusions: (1) very good accuracy was obtained in the measurement of different $U$ isotopes (in all the cases, the standard deviations were lower than $4 \%$ ); and (2) ${ }^{234} \mathrm{U}$ in these samples was clearly detected, with counting values at least 10 times higher than that in the blank sample.

These data made us confident in calculating the isotopic and activity ratios of $U$ isotopes. The results are summarised in Table 5. Average values determined in a set of aliquots of the same phosphogypsum samples by alpha-spectrometry are also given. ${ }^{30}$ From the results obtained previously, a secular equilibrium was found between ${ }^{234} \mathrm{U}$ and ${ }^{238} \mathrm{U}$, and the ${ }^{235} \mathrm{U}^{238} \mathrm{U}$ activity ratio was 0.047 , which is expected in natural samples.

We concluded that, at the $\mathrm{U}$ concentrations existing in the final measured solutions (in the range $35-70 \mathrm{ppb}$ ), the ${ }^{238} \mathrm{U} /{ }^{234} \mathrm{U}$ isotopic ratios can be measured with good accuracy. These ratios agree with those previously determined by alphaspectrometry. Due to the presence of a higher number of ${ }^{235} \mathrm{U}$ atoms in comparison with ${ }^{234} \mathrm{U}$, the ${ }^{238} \mathrm{U} /{ }^{235} \mathrm{U}$ isotopic ratios can also be determined with high precision by ICP-MS.

The results show the capability of the ICP-MS method developed in this work for the determination of the ${ }^{238} \mathrm{U} /{ }^{234} \mathrm{U}$ ratio at the concentration levels described. Concerning the measurement time, the ICP-MS method can be considered superior to other traditional radiometric techniques, e.g.,

Table 5 Mass and activity uranium isotopic ratios obtained in the measurements of three phosphogypsum samples. The average values for these isotopic ratios, determined by alpha-spectrometry, are also listed

\begin{tabular}{|c|c|c|c|c|}
\hline Sample & ${ }^{238} \mathrm{U} /{ }^{234} \mathrm{U}$ mass ratio & ${ }^{238} \mathrm{U} /{ }^{235} \mathrm{U}$ mass ratio & ${ }^{234} \mathrm{U} /{ }^{238} \mathrm{U}$ activity ratio & ${ }^{235} \mathrm{U} /{ }^{238} \mathrm{U}$ activity ratio \\
\hline $\mathrm{C}$ & $18601 \pm 681$ & $144 \pm 4$ & $1.00 \pm 0.04$ & $0.044 \pm 0.001$ \\
\hline $\mathrm{D}$ & $18884 \pm 847$ & $144 \pm 3$ & $0.98 \pm 0.04$ & $0.044 \pm 0.001$ \\
\hline $\mathrm{E}$ & $18967 \pm 588$ & $147 \pm 4$ & $0.98 \pm 0.03$ & $0.043 \pm 0.001$ \\
\hline Alpha-spectrometry $^{a}$ & $18550 \pm 370$ & $139 \pm 3$ & $1.00 \pm 0.02$ & $0.047 \pm 0.002$ \\
\hline
\end{tabular}


alpha-spectrometry. In fact, to obtain the same accuracy by alpha-spectrometry a count time of at least $72 \mathrm{~h}$ is necessary, assuming $100 \%$ recovery yield and $0.1 \mathrm{~g}$ of phosphogypsum. This figure must be compared with $10 \mathrm{~min}$, which is the typical counting used along this work. Besides, if the determination of the ${ }^{238} \mathrm{U}^{235} \mathrm{U}$ ratio is also of interest, ICP-MS can obtain it accurately because the radioactivity of ${ }^{235} \mathrm{U}$ is clearly lower than that of ${ }^{234} \mathrm{U}$ in the samples.

\section{Acknowledgements}

One of the authors (RGT) gratefully acknowledges the financial support of the Science Technology Agency of Japan for a scientific visit to the Institute of Radiological Sciences in Nakaminato. RGT is also very grateful to all the staff of this institute for their help and warm hospitality.

\section{References}

1 Y. Igarashi, C. K. Kim, Y. Takaku, K. Shiraishi, M. Yamamoto and N. Ikeda, Anal. Sci., 1990, 6, 157.

2 T. Yoshida, S. Yamasaki and A. Tsumura, J. Miner. Petrol. Econ Geol., 1992, 87, 107.

3 S. Yamasaki, A. Tsumura and Y. Takaku, Microchem. J., 1994, 49, 305.

4 S. Yoshida, Y. Muramatsu, K. Tagami and S. Uchida, Int. J. Environ. Anal. Chem., 1996, 63, 195.

5 K. Shiraishi and F. McInroy, J. Trace Elements Exp. Med., 1991, 4, 191.

6 S. Morita, C. K. Kim, Y. Takaku, R. Seki and N. Ikeda, Int. J. Appl. Radiat. Isot., 1991, 42, 531.

7 K. Tagami and S. Uchida, Radiochim. Acta, 1993, 63, 69.

8 J. S. Crain, L. L. Smith, J. S. Yaeger and J. A. Alvarado, J. Radioanal. Nucl. Chem., Articles, 1995, 194, 133.

9 S. Yoshida and Y. Muramatsu, Int. J. Environ. Anal. Chem., 1998, 67, 49.

10 C. K. Kim, R. Seki, S. Morita, S. Yamasaki, A. Tsumura,
Y. Takaku, Y. Igarashi and M. Yamamoto, J. Anal. At. Spectrom., 1991, 6, 205.

11 J. S. Becker, R. S. Soman, K. L. Sutton, J. A. Caruso and H.-J. Dietze, J. Anal. At. Spectrom., 1999, 14, 933.

12 J. S. Becker and H.-J. Dietze, J. Anal. At. Spectrom., 1999, 14, 1493.

13 S. Yamasaki and A. Tsumura, Anal. Sci., 1991, 7, 1135.

14 Y. Muramatsu, K. Tagami and S. Uchida, J. Radioanal. Nucl. Chem., Lett., 1994, 188, 305.

15 M. Y. Pérez-Jordán, J. Soldevila, A. Salvador, A. Pastor and M. Guardia, J. Anal. At. Spectrom., 1998, 13, 33.

16 A. J. Walder and P. A. Freedman, J. Anal. At. Spectrom., 1992, 7, 571.

17 I. S. Begley and B. L. Sharp, J. Anal. At. Spectrom., 1994, 9, 171

18 W. Kerl, J. S. Becker, H.-J. Dietze and W. Dannecker, Fresenius J. Anal. Chem., 1997, 359, 407.

19 S. Joannon, P. Telouk and C. Pin, Spectrochim. Acta, Part B, 1997, 52B, 1783.

20 J. S. Becker and H.-J. Dietze, Fresenius' J. Anal. Chem., 1999, 364 482.

21 A. J. Walder, D. Koller, N. M. Reed, R. C. Hutton and P. A. Freedman, J. Anal. At. Spectrom., 1993, 8, 1037.

22 G. P. Puss III and J. M. Bazan, Spectrochim. Acta, Part B, 1987, 42B, 49.

23 M. Ivanovich and A. Murray, in Uranium Series Disequilibrium: Applications to Earth. Marine and Environmental Sciences, ed. M. Ivanovich and R. S. Harmon, Clarendon Press, Oxford, 1992, ch. 5 .

24 A. Martínez-Aguirre, M. García-León and M. Ivanovich, J. Environ. Radioact., 1994, 22, 155.

25 E. P. Horwitz, M. L Dietz, R. Chiarizia, H. Diamond S. L. Maxwell III and M. R. Nelson, Anal. Chim. Acta, 1995, 310, 63.

26 E. P. Horwitz, R. Chiarizia, M. L. Dietz and H. Diamond, Anal. Chim. Acta, 1993, 281, 361.

27 T. Sato, J. Sato and T. Nakamura, Radioisotopes, 1997, 46, 331.

28 H. E. Carter, A. Warwick, J. Cobb and G. Longworth, Analyst, 1999, 124, 271.

29 P. Goodall and C. Lythgoe, Analyst, 1999, 124, 263.

30 R. García-Tenorio and M. García-León, unpublished data. 